Article

\title{
Infrared Thermography for Inline Monitoring of Glass/Epoxy under Impact and Quasi-Static Bending
}

\author{
Carosena Meola * (iD), Simone Boccardi and Giovanni Maria Carlomagno (iD \\ Department of Industrial Engineering, Aerospace Division, University of Naples Federico II, 80138 Naples, Italy; \\ simone.boccardi@unina.it (S.B.); carmagno@unina.it (G.M.C.) \\ * Correspondence: carmeola@unina.it; Tel.: +39-081-768-3621
}

Received: 23 January 2018; Accepted: 9 February 2018; Published: 19 February 2018

Featured Application: The scope of this work is to show the potential of infrared thermography to collect important information to be exploited for the characterization of new composite materials. An infrared imaging device can be included in most mechanical test setups for the in-line monitoring of samples undergoing either impact or quasi-static bending, or else fatigue tests. As an important assertion, the use of infrared thermography allows for fast inspection of relatively large surfaces in a remote way without any alteration of the inspected part and without safety-at-work concerns.

\begin{abstract}
In this work, glass/epoxy has been chosen as case study as it represents the most-used composite material, being appropriate for a vast variety of applications and a reasonable performance/cost compromise. This material has already been inline impact-monitored with infrared thermography, mostly for feasibility tests. Now, impact tests are repeated by changing some parameters and by inline monitoring simultaneously with two different infrared cameras to share a high frame rate and spatial resolution at the same time. In addition, glass/epoxy is monitored also while it is under quasi-static bending tests. The aim of this paper is to show what it is possible to learn from thermal signatures developing in the same material when it is either impacted or under quasi-static bending.
\end{abstract}

Keywords: composites; glass fiber reinforced polymer (GFRP); impact tests; quasi-static bending; infrared thermography

\section{Introduction}

In today's era-in which the imperatives are light, small and smart-composites are ever more dominating the materials scene. They offer many advantages over metals and other more conventional materials. As a primary benefit, a composite can be easily tailored to assume specific characteristics and shapes [1,2] to fulfil the user's demand. In fact, a composite material is made of two basic constituents: the matrix and the reinforcement. The first acts as an envelope while the second mostly provides the strength. By changing the properties of one of them (appropriate choice), or of both, it is possible to obtain a material of the desired stiffness, strength, impact resistance, etc. In addition, a desired shape can be easily achieved through molds, which are filled with soft plies and later subjected to curing. The two constituents can be derived from petrochemical resources, or extracted from the vegetable world, which also allows for compliance with safety-at-work concerns and waste disposal [3-5]. The matrix may be made of either epoxy resin, polypropylene, polyethylene (from petrochemicals), or polylactic acid (PLA) (from renewable resources such as cornstarch, tapioca, or sugarcane). The reinforcement may include different types of fibers: glass, carbon, jute, flax, etc.

Basically, a new material can be quite easily manufactured, but its characteristics, performance in service, as well its suitability to a specific application field cannot be straightforwardly 
established even if it is made of constituents with well-known characteristics. The final product must undergo characterization from different points of view: chemical, mechanical, thermal, etc. Composites, at least thermoset matrix-based ones, are vulnerable to impact damage [6,7]. Most crucial is the barely visible impact damage (BVID) [8], which, if it remains undetected, may lead to early unpredicted failure. The impact damage mechanisms are complex and not yet completely understood. Therefore, to successfully design damage-tolerant composite structures, it is necessary to have a reliable analysis tool to aid in understanding the complex phenomena that take place and is capable of estimating the consequences of an impact [9]. This is still an open question, despite the available broad literature, which involves analytical, experimental and numerical approaches [10-15].

Complete knowledge of a material is a lengthy and difficult process, requiring different types of expertise and expensive tests; difficulties arise especially in experimental round-robin tests because of the involved costs. Within this context, infrared thermography (IRT) can be advantageously exploited as a non-destructive technique (NDT) and as per in-line monitoring (ILM) of several mechanical tests.

The research group at the University of Naples Federico II is involved with both NDT and ILM and, in particular, has been amongst the first to perform ILM of impact [16] and cyclic bending [17] tests of different types of composite materials, as well as, more recently, quasi-static bending of PLA/jute [18]. With regard to glass/epoxy materials, the investigation has been limited to impact tests. More specifically, glass/epoxy was initially used for feasibility tests; the obtained results were successful and opened the way to the possibility of IRT to contribute to either validate previous theories on impact damaging of composites, or discover new aspects of the behavior of a composite material under mechanical stresses. To get the best results, it is important to use the most appropriate infrared camera and to account for the instrument noise. Of course, for performance assessment, a comparison with data coming from other laboratories and research groups around the world would be desirable, but unfortunately, there is still a lack of data. The available literature regards mainly nondestructive testing; inline monitoring is mostly concerned with thermo-elastic stress analysis (TSA) or fatigue tests. The investigation, which may appear closer to our topic, is concerned with quasi-static tensile tests [19], but involves a hybrid composite, which cannot be exploited for fruitful comparison.

In the present paper, impact tests of glass/epoxy are performed with contemporaneous inline monitoring with two different infrared cameras to share a high frame rate and spatial resolution for a better visualization of related thermal effects. In addition, the same material is now, for the first time, inline monitored while being subjected to quasi-static bending tests. Thus, the scope of this work would be an overview of some of the main features which can be identified with an infrared imaging device and which can be exploited to broaden our knowledge about composite materials damaging mechanisms.

\section{Materials and Methods}

The material considered here is basically a glass fiber reinforced polymer (GFRP) including unidirectional E-glass fibers $\left(300 \mathrm{~g} / \mathrm{m}^{2}\right)$ and low viscosity epoxy resin (MATES ${ }^{\circledR}$ SX10, Italy). More specifically, eight epoxy impregnated E-glass plies are hand lay-up stacked at $\left[0^{\circ}{ }_{2}, 90^{\circ}{ }_{2}\right]_{\mathrm{s}}$ to obtain an overall specimen thickness of $2.9 \mathrm{~mm}$; curing is performed under pressure at ambient temperature. The main peculiarity of this GFRP material is to be translucent, allowing eyesight of imperfections for a direct comparison with results supplied by infrared thermography. The dimensions of the specimens are $100 \mathrm{~mm} \times 130 \mathrm{~mm}$, or $30 \mathrm{~mm} \times 130 \mathrm{~mm}$, depending on the type of test: impact, or quasi-static bending, respectively.

Impact tests are carried out with a modified Charpy pendulum [20], which is equipped with a special fixture to lodge specimens and allow for the contact with the hammer from one side and optical view (by the infrared camera) from the other one. In particular, a small sample of the same material is positioned over one corner of the viewed window and is used as reference to correct the camera noise. The hammer has a hemispherical shaped nose, $12.7 \mathrm{~mm}$ in diameter; values of the impact energy $E$ are set by suitably adjusting the falling height of the Charpy arm. 
Two infrared cameras are used, the SC6000 and the SC6800 (Flir systems), with images acquired at frame rate of 83 and $960 \mathrm{~Hz}$, respectively. Sequences of thermal images are picked up during the impact event; or better, to allow for a complete visualization of the evolution of thermal effects with respect to the initial ambient temperature, the acquisition would start before the impact and last for some time after. Having two sequences at two different frame rates for each test is appropriate to analyze either the thermo-elastic phase (which is fast), or the plastic one (which is slower), by considering one sequence or the other. More specifically, it is possible to get information on the thermo-elastic phase by relating to images recorded at the higher speed during the first fractions of a second after the impact. Conversely, attention reverts to the sequence recorded at lower speed to analyze the slower evolving thermo-plastic phenomena, without unnecessary overloading of the computer memory. A supplementary video S1 (GFRP-12J) taken with the SC6800 camera of a specimen impacted at 11.7 J is supplied for the online version.

Quasi-static bending tests are carried out with a standard three-point bending configuration set-up. The specimen is horizontally placed over two supports at a mutual distance of $50 \mathrm{~mm}$ and loaded downwards in the middle at a speed of $5 \mathrm{~mm} / \mathrm{min}$ with a $5 \mathrm{~mm}$ radius loading nose. The infrared camera views the specimen at about $45^{\circ}$, so to contemporaneously include both its bottom flat surface and its thickness (side view). Sequences of thermal images are recorded at $30 \mathrm{~Hz}$ with the handheld Flir systems T650sc camera.

The images are post-processed to extract information about the material thermal behavior. Post-processing is performed by using the ResearchIR software supplied with the infrared cameras and routines specifically developed in the Matlab environment. In particular, the two sets of image sequences acquired during the two types of tests refer to either a static object, or a deforming one, which require a different handling. In particular, from sequences acquired during impact tests, the influence of the ambient temperature is removed by subtracting an image taken at environmental conditions (before starting of impact tests) from all the subsequent images of the sequence; thus a sequence of $\Delta T$ images is created. Specific post-processing is discussed in the next section.

\section{Results}

\subsection{Impact Tests}

Some $\Delta T$ images taken with the SC6800 camera (at the higher frame rate) of a specimen impacted at $E=8.3 \mathrm{~J}$ are shown in Figure 1. As can be seen, initially (before impact), the specimen surface is at almost uniform $\Delta T=0$ (Figure 1a) while, suddenly at the impact, a dark zone appears, accounting for material bending (Figure 1b). Such a dark zone enlarges with time as the surface bending proceeds and gets dotted with lighter points (Figure 1c-e), which most probably indicates the presence of porosity. The skin over a pore thins with the increasing of the surface curvature and breaks once the thinning limit is reached; this happens first in two central dots (hot spots of Figure 1f) which are the mostly stressed and mark the begginning of the damage. Afterward, the dark zone enlarges, as also the two hot spots do, while another hot spot appears (Figure 1g). Later on, the dark zone starts to shrink while the area around the hot spots gets warmer (Figure $1 \mathrm{~h}-\mathrm{k}$ ); finally, the dark zone is replaced by a warm zone (Figure 11). 


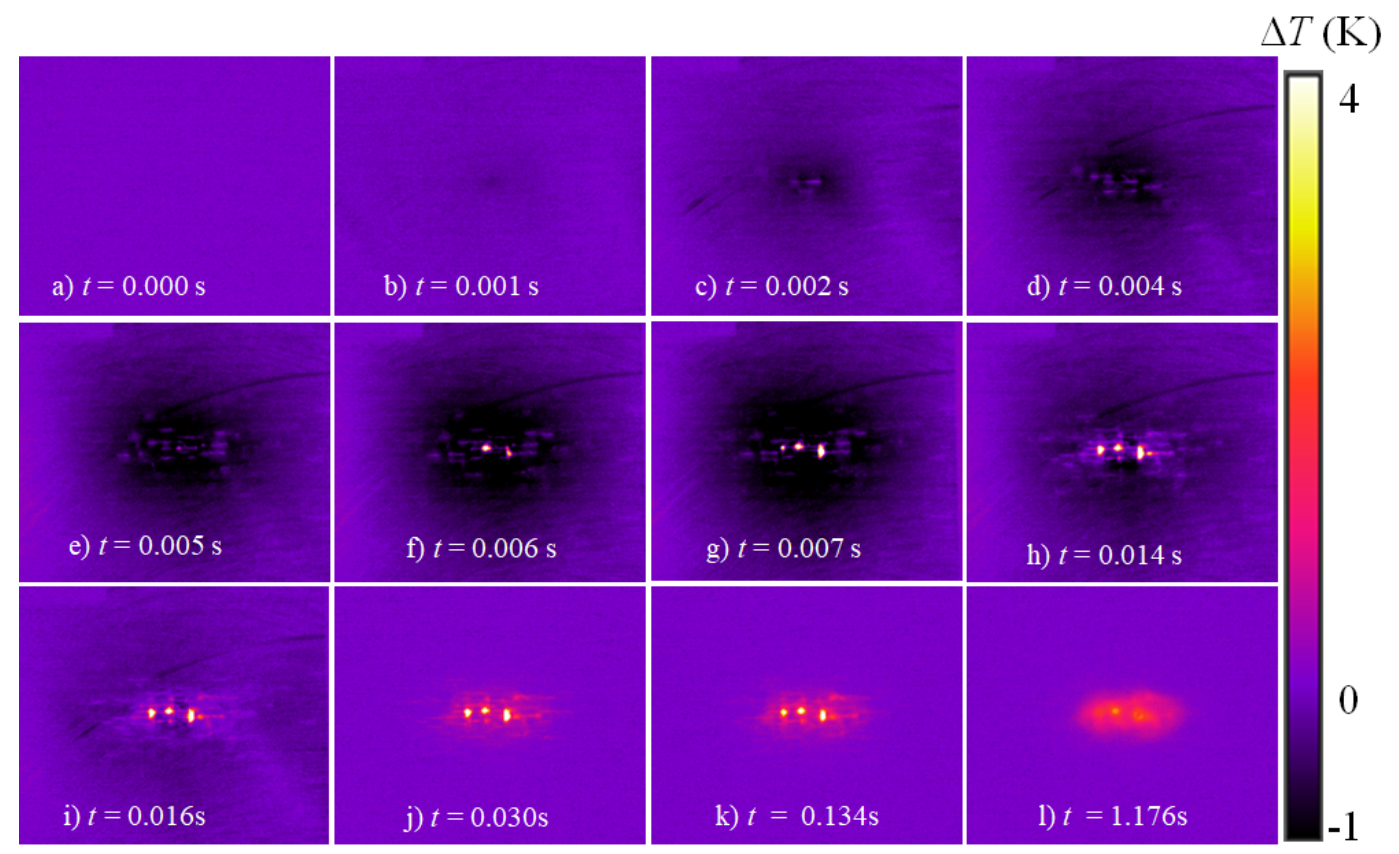

Figure 1. Some $\Delta T$ images, taken at different time instants with the SC6800 camera, of a specimen impacted at $E=8.3 \mathrm{~J}$.

To better display the above described effects, $\Delta T$-time plots in four key points $\mathrm{A}, \mathrm{B}, \mathrm{C}$ and $\mathrm{D}$ are shown in Figure 2 and, to highlight the fibers involved in the breakage, a $\Delta T$ image taken with the SC6000 camera at higher spatial resolution (viewing a reduced area) is reported in Figure 3. It is possible to clearly see the fiber misalignment and the location of hot spots over one bundle of fibers, or at the junction of misaligned fibers.

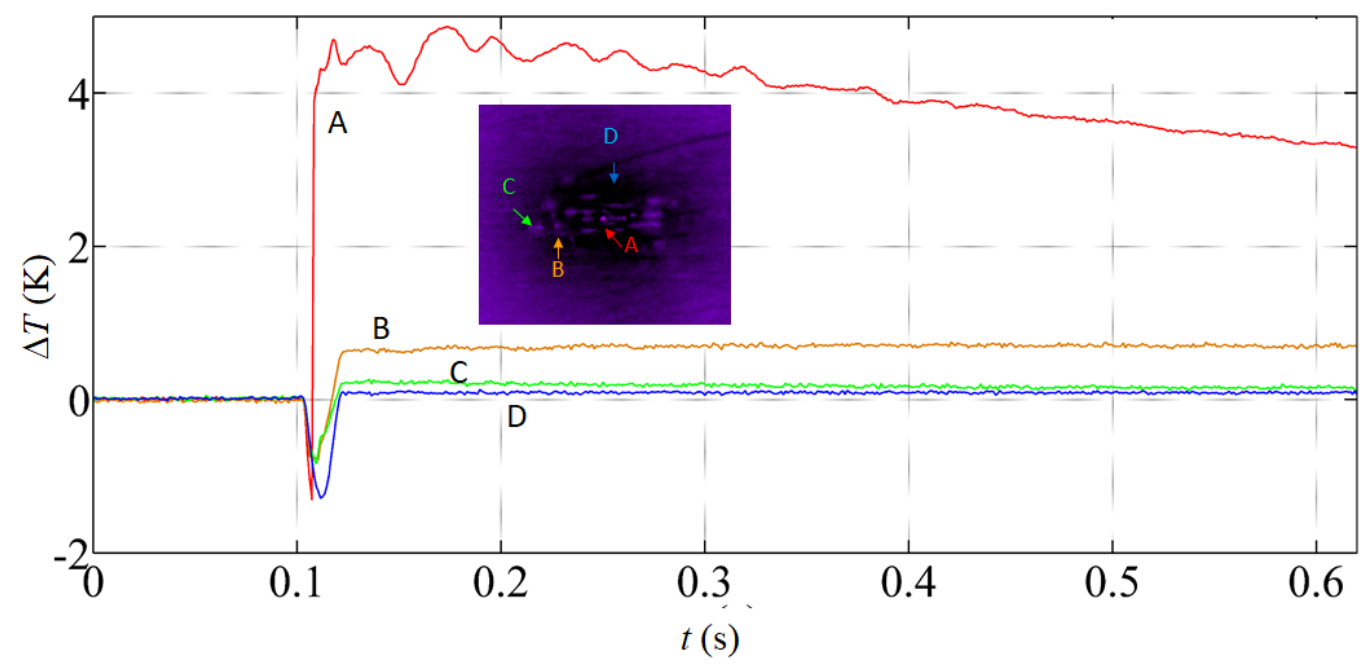

Figure 2. $\Delta T$-time plots in four points $\mathrm{A}, \mathrm{B}, \mathrm{C}$ and $\mathrm{D}$ of a specimen impacted at $E=8.3 \mathrm{~J}$. 


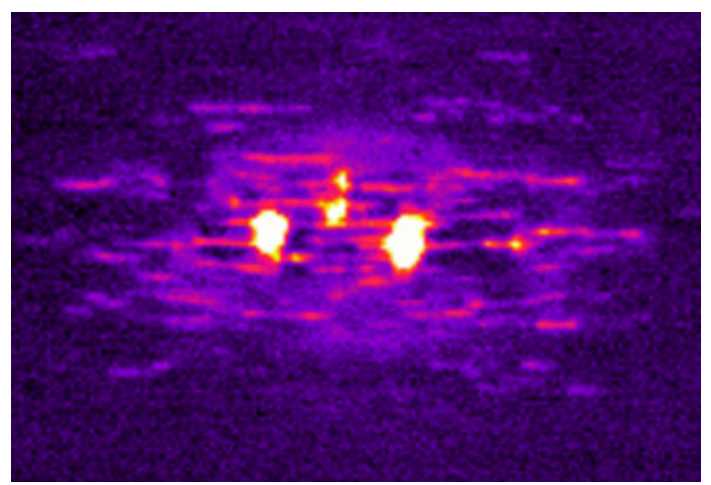

Figure 3. A higher spatial resolution $\Delta T$ image taken at $t=0.036 \mathrm{~s}$ with the SC6000 camera of a specimen impacted at $E=8.3 \mathrm{~J}$.

Minima and maxima (resp. $\Delta T_{\text {Min }}$ and $\Delta T_{\text {Max }}$ ) time plots are also extracted from $\Delta T$ images recorded at the highest frame rate with the SC6800 camera and reported in Figure 4. By analysing these plots, more details about the material damaging under impact can be derived. In particular, $\Delta T_{\text {Min }}$ (negative) values describe a concavity, having a width $\Delta t$ along the $\mathrm{x}$ axis and a peak (height, $t_{\mathrm{p}}$ ) along the $y$ axis; $t_{\mathrm{p}}$ identifies the instant the impactor reaches its strongest pushing force, or better the peak contact force $[11,21,22]$. Besides this, the appearance of the first hot spot $(\Delta T>0)$ is generally concurrent with the formation of micro-cracks in the matrix, and this may occur before the surface reaches its maximum curvature $\left(t_{\mathrm{p}}\right)$ for a given $\mathrm{E}$ value. The $\Delta T_{\mathrm{Max}}$ peak value increases with $E$.
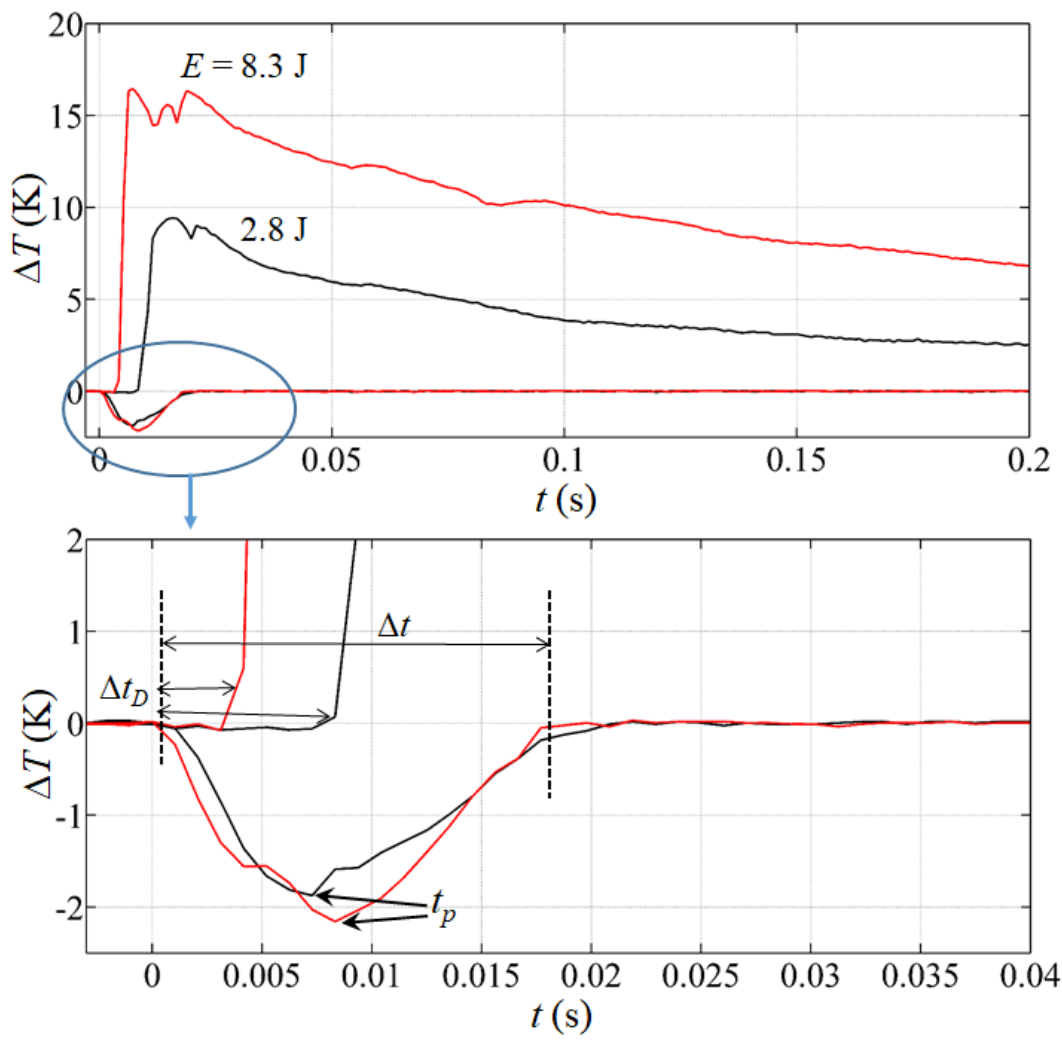

Figure 4. $\Delta T$-time plots; a comparison between $\Delta T_{\mathrm{Max}}$ and $\Delta T_{\mathrm{Min}}$ distributions for $E=2.4$ and $8.3 \mathrm{~J}$ on the top; a magnification to show $\Delta t, \Delta t_{\mathrm{D}}$ and $t_{\mathrm{p}}$ parameters on the bottom.

$\Delta T_{\text {Max }}$ and $\Delta T_{\text {Min }}$ are searched for in a region wide enough to include either the zone with cracks in progress or the zone which continues to bend leading to the $\Delta T_{\text {Min }}$ peak before the end of impact. 
It is worth noting that a $\Delta t_{\mathrm{D}}$ value, even a small one, is always present, as this investigation is focused on low velocity/energy impact; instead, at high velocity/energy with material breakage suddenly at impact, the heating phase may practically start almost with the cooling one, i.e., $\Delta t_{\mathrm{D}} \approx 0$. As the impactor moves back, the surface tends to restraighten and, as it recovers its unbent configuration, any cooling effect disappears $\left(\Delta T_{\mathrm{Min}} \rightarrow 0\right)$. The two sides of the concavity-descent and ascent-are almost equal with respect to the $t_{p}$ value, with the ascent one slightly longer. By comparing $\Delta T_{\text {Min }}$ and $\Delta T_{\text {Max }}$ distributions for $E=8.3 \mathrm{~J}$, it is possible to see a correspondence between $\Delta t_{\mathrm{D}}$ and the knee in $\Delta T_{\text {Min }}$, as well the first $\Delta T_{\text {Max }}$ peak and $t_{\mathrm{p}}$. At the lowest $2.8 \mathrm{~J} \mathrm{impact} \mathrm{energy,} \Delta t_{\mathrm{D}}$ is almost equal to $t_{\mathrm{p}}$. Generally, the first $\Delta T_{\text {Max }}$ peak lies in correspondence with the $\Delta T_{\text {Min }}$ peak, while secondary $\Delta T_{\text {Max }}$ peaks occur later when $\Delta T_{\text {Min }}$ is in its ascent phase. The first $\Delta T_{\text {Max }}$ peak is surely to be ascribed to breakage of the material when it is under tensile stress, while secondary peaks may also be caused by frictions at the broken borders when the surface tends to recover its undeformed shape.

The $\Delta T$ images recorded at the lower frame rate with the SC6000 camera are exploited for the evaluation of the warm area extension, which also bears witness to the extension of the delaminated area. The warm area is measured by applying the noise correction reference (NCR) method, which roughly consists in comparing a $\Delta T$ image taken after impact with one taken before. Actually, the method is more complex, requiring correction $\left(\Delta T_{C}\right)$ for temporal noise. In particular, the $\Delta T_{\mathrm{CR}}$ image (before impact) is the average over $100 \Delta T_{\mathrm{C}}$ images and their standard deviation $\sigma$ is evaluated, while $\Delta T_{\mathrm{CW}}$ (after impact) is the average over $\Delta T_{\mathrm{C}}$ images collected in $0.602 \mathrm{~s}$, by discarding images with cold (below ambient) zones. Then, a $\Delta T_{\mathrm{CW}}$ image is transformed into a black/white binary image in which any pixel can assume a value equal to either 0 , or 1 , i.e., whether it is cold (black), or warm (white), respectively, according to the following rule:

$$
\left\{\begin{array}{l}
\Delta T_{\mathrm{cw}}(i, j)>\Delta T_{\mathrm{CR}}(i, j)+3 \sigma(\mathrm{i}, \mathrm{j}) \text { pixel }=1 \\
\Delta T_{\mathrm{cw}}(i, j) \leq \Delta T_{\mathrm{CR}}(i, j)+3 \sigma(\mathrm{i}, \mathrm{j}) \text { pixel }=0
\end{array} .\right.
$$

More information can be found in ref [23]. The warm area perimeter is also extracted with the bwperim Matlab function and superimposed on a $\Delta T_{\mathrm{CW}}$ image. An example of a contoured $\Delta T_{\mathrm{CW}}$ image is shown in Figure 5 with also a photo of the impacted specimen. Epoxy resin being translucent, it is possible to see as the impact damage footprint practically matches the contoured warm area.

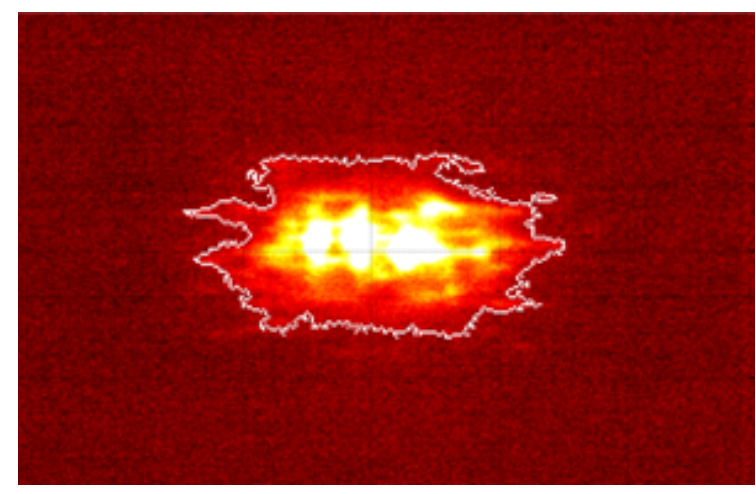

(a)

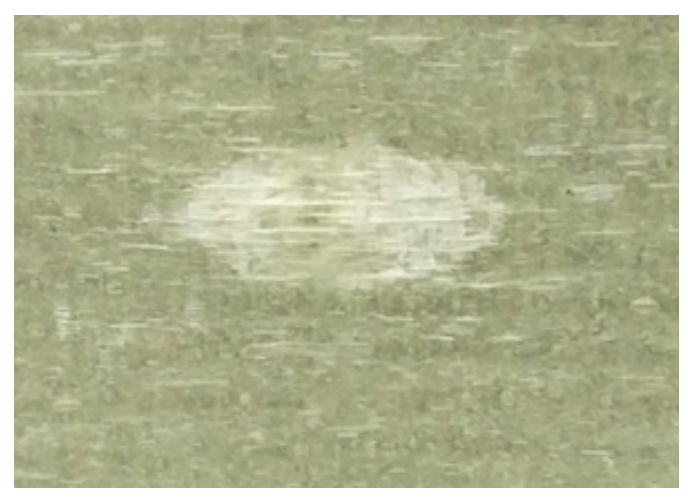

(b)

Figure 5. Comparison between contoured image (a) and photo of the rear to impact specimen surface (b) for $E=8.3 \mathrm{~J}$.

Once contoured, the warm area $A_{\mathrm{h}}$ is obtained by counting the enclosed number of hot pixels $\mathrm{P}_{\mathrm{h}}$ and considering the camera spatial resolution $\mathrm{s}_{\mathrm{r}}$ through the relationship:

$$
A_{\mathrm{h}}=P_{h} s_{r}^{2}
$$


$A_{\mathrm{h}}$ values are collected in Table 1 with the absolute maximum values of $\Delta T_{\mathrm{Max}}$ and $\Delta T_{\text {Min }}$ and the above defined parameters. As can be seen, excluding the value for $E=2.8 \mathrm{~J}$, the ratio between the impact energy and $A_{\mathrm{h}}$ assumes an almost constant value. The $A_{\mathrm{h}}$ value of the specimen impacted at the lowest energy may appear as excessive, but it can be explained considering that the extension of delamination depends mostly on the conditions of the impacted surface and not only on the impact energy. Of great importance is the presence of defects in the material such as fiber misalignement, poor, or rich, resin zones, pores, etc. which may affect the interply cohesive force. Therefore, the presence of defects may entail also differences in $\Delta T_{\text {Max }}$ values leading, for example, to a lower value in response to a higher $E$ value since the impact energy, which is dissipated as internal energy, and is spent in the formation of matrix microcracks, delamination and rupture of fibres. As a general indication, light delamination is accompanied by small temperature rise, in general a $\Delta T$ not greater than $2 \mathrm{~K}$; higher $\Delta T$ values are indicative of more important damage.

Table 1. Some data for varying impact energy.

\begin{tabular}{cccccccc}
\hline$E(\mathbf{J})$ & $A_{\mathbf{h}}\left(\mathbf{m m}^{\mathbf{2}}\right)$ & $E / A_{\mathbf{h}}\left(\mathbf{J} / \mathbf{m m}^{\mathbf{2}}\right)$ & $\Delta T_{\text {Min }}(\mathbf{K})$ & $\Delta T_{\text {Max }}(\mathbf{K})$ & $\Delta t(\mathbf{s})$ & $\Delta t_{D}(\mathbf{s})$ & $t_{p}(\mathbf{s})$ \\
\hline 2.8 & 206 & 0.0136 & -1.9 & 9 & 0.021 & 0.007 & 0.007 \\
8.3 & 467 & 0.0178 & -2.1 & 16 & 0.019 & 0.003 & 0.008 \\
11.7 & 580 & 0.0207 & -2.2 & 17 & 0.019 & 0.003 & 0.008 \\
15.0 & 743 & 0.0202 & -1.8 & 11 & 0.019 & 0.003 & 0.008 \\
\hline
\end{tabular}

\subsection{Quasi-Static Bending Tests}

Some thermal images taken during quasi-static bending tests are shown in Figure 6. It has to be pointed out that, in each image, the upper part (about $15 \%$ of the total coloured band height) gives the temperature across the specimen thickness, while, moving down, the temperature distribution on the bottom surface, viewed at $45^{\circ}$, is represented (Figure 7). Each image is labelled with the time at which it is taken; time is counted starting with the load application. An attempt to synchronize the loading machine's startup with image recording was manually performed without triggering. However, synchronization can be assumed as fulfilled considering the frame rate of $30 \mathrm{~Hz}$ against the machine speed of $5 \mathrm{~mm} / \mathrm{min}$.

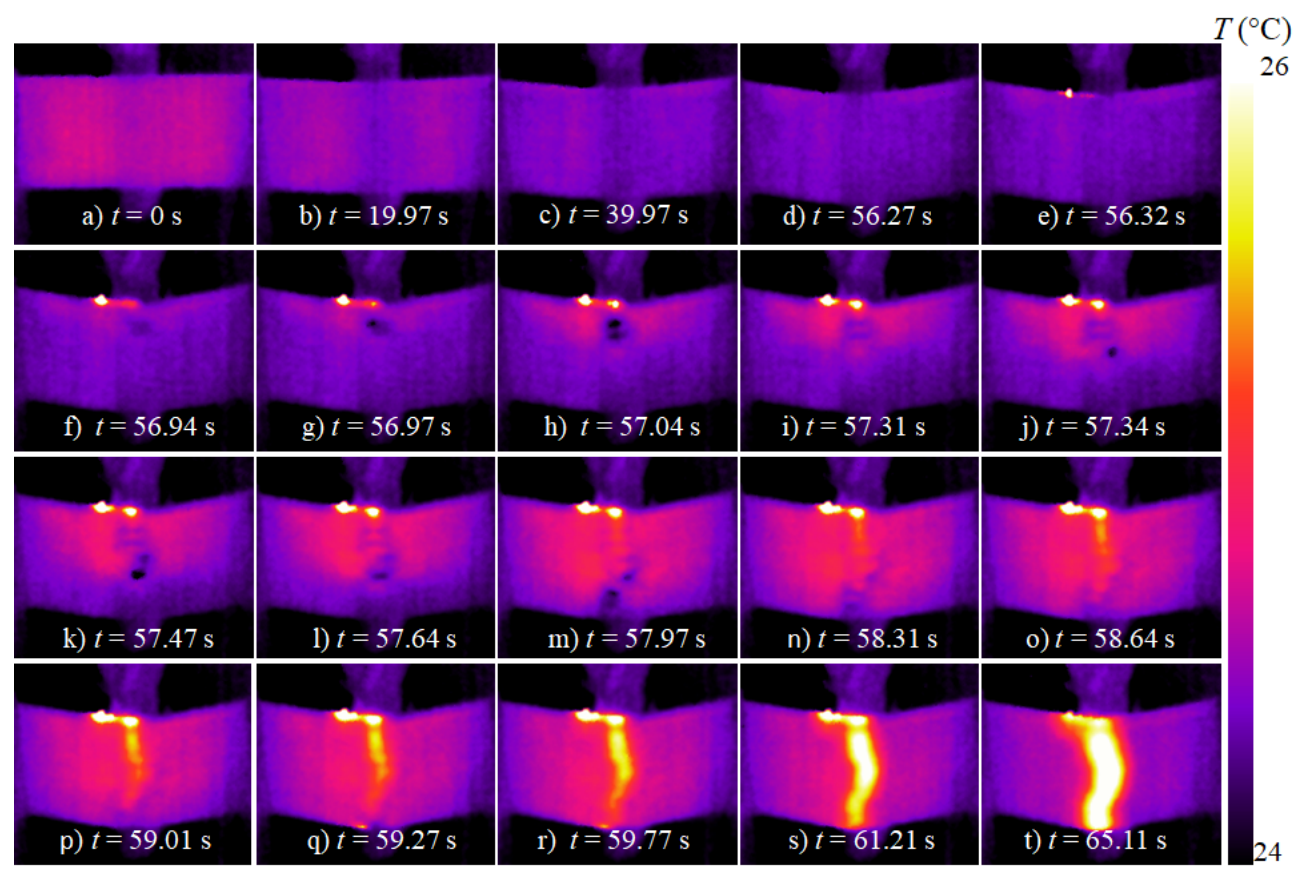

Figure 6. Some thermal images taken at several time instants during quasi-static bending. 


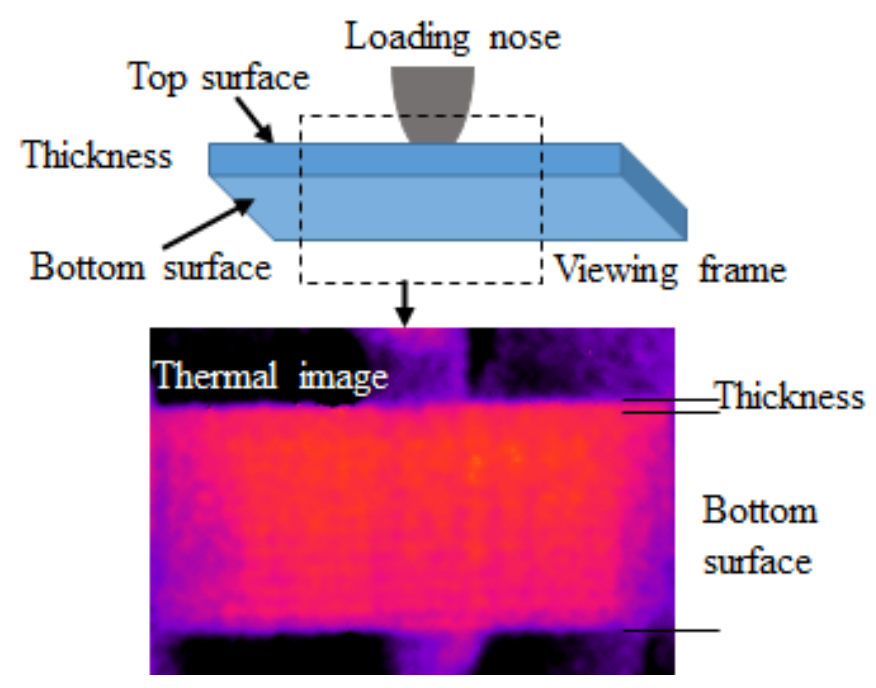

Figure 7. Sketch of quasi-static bending configuration and viewing frame.

As can be seen, the first image (Figure 6a) gives an almost uniform temperature (ambient temperature), indicating that the specimen is still in its unbent condition. The darker central zone in the second image (Figure 6b), which shows a cooling-down, bears witness to the specimen deformation; this can also be ascertained by looking at the top border, which starts to appear curved with respect to that of the first image. Of course, the border's curvature increases with time as the pushing nose moves down; in the meantime, cooling down enlarges to practically include the entire viewed surface (Figure $6 \mathrm{c}, \mathrm{d}$ ). It has to be stressed that, since the loading machine speed is relatively low, all detected temperature variations have the time somehow to release and are weaker than the theoretical ones.

As the critical curvature is reached, the material breakage initiates. The hot spot of Figure 6e indicates that breakage starts on top, at the left of the pushing nose, and, afterwards, another one appears at the specimen centre (Figure 6f). These hot spots appear on the top of the material thickness, while the specimen undergoes further bending (accounted for by local cooling down). Finally, the bottom surface is also followed by a strong warming-up. The temperature variations with time depict the material failure; in fact, under quasi-static bending, glass/epoxy generally breaks on the pushing side (top surface). The failure initiation is suddenly visualized, looking at the specimen thickness, while any temperature variation on the opposite side appears much later, driven by breakage propagation as well as the material thermal diffusivity. To better show this behaviour, a two-points plot is reported in Figure 8 with a key image replicated from Figure 6.

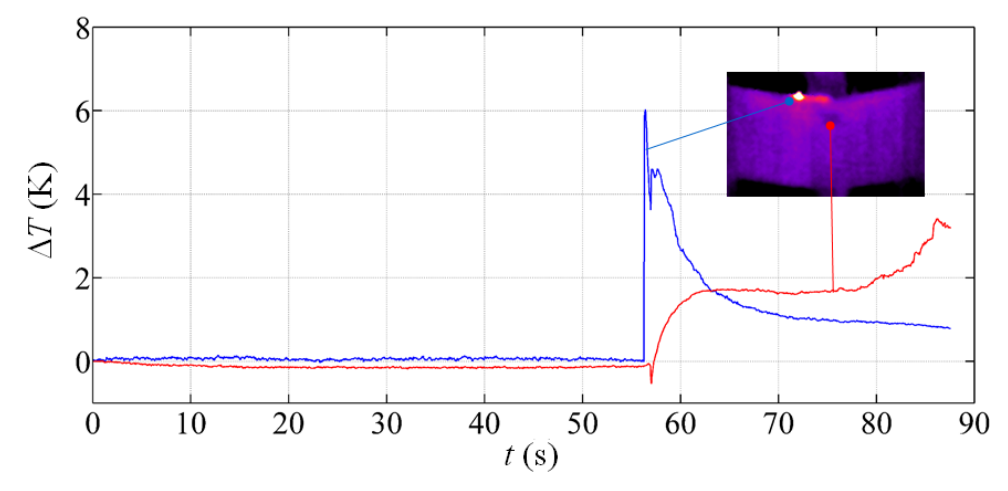

Figure 8. A two-points temperature plot: the blue curve refers to a point over the top specimen surface; the red curve refers to a point over the bottom specimen surface. 
To establish a correspondence between temperature rise and material modifications, the force curve (black), measured by the loading machine, is reported in Figure 9 superimposed on the $\Delta T_{\text {Max }}$ distribution (red) visualized by the infrared camera. In particular, the $\Delta T_{\text {Max }}$ distribution is obtained by extracting the maximum temperature value in each image with respect to the ambient value of the first image. As can be seen, the change in slope of the force curve corresponds to a temperature variation. In particular, there is a sudden temperature rise (first peak) in correspondence with the force curve inversion. The first peak refers to the hot spot in the specimen thickness, accounting for failure initiation. The other peaks refer to local breakages afterwards occurring, as well to frictional effects at the interface of the specimen broken parts.

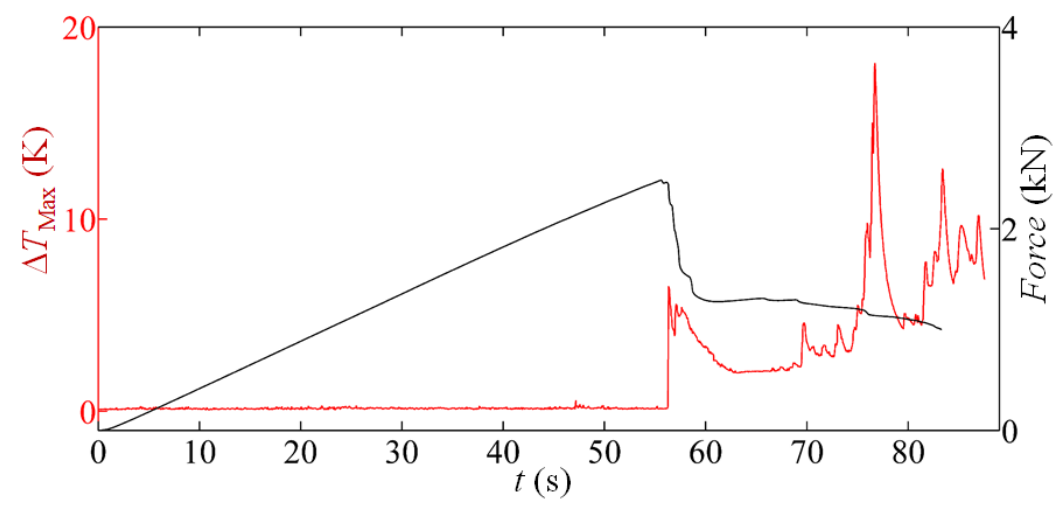

Figure 9. A comparison between force distribution (black) and maximum surface temperature $\left(\Delta T_{\operatorname{Max}}\right)$ distribution (red).

Figure 10 shows photographs of both specimen surfaces: the top one in contact with the pushing nose (Figure 10a) and the bottom one on the other side (Figure 10b). It is possible to notice a good correspondence between the damage footprints on both sides and with also the warm zone of Figure $60-\mathrm{t}$.

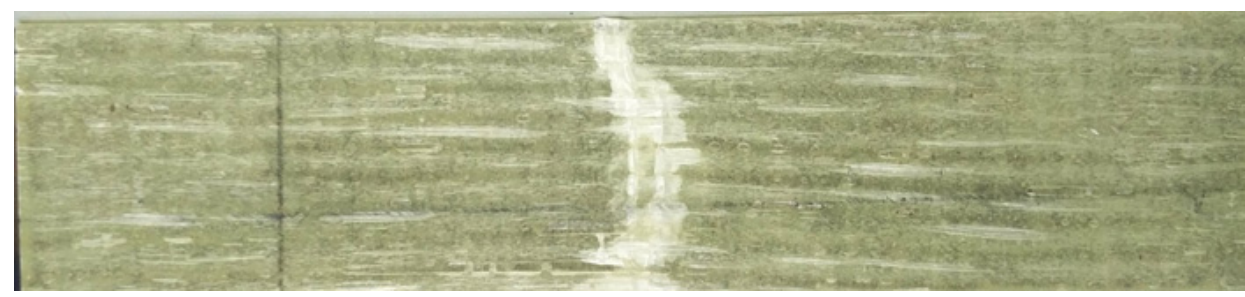

(a)

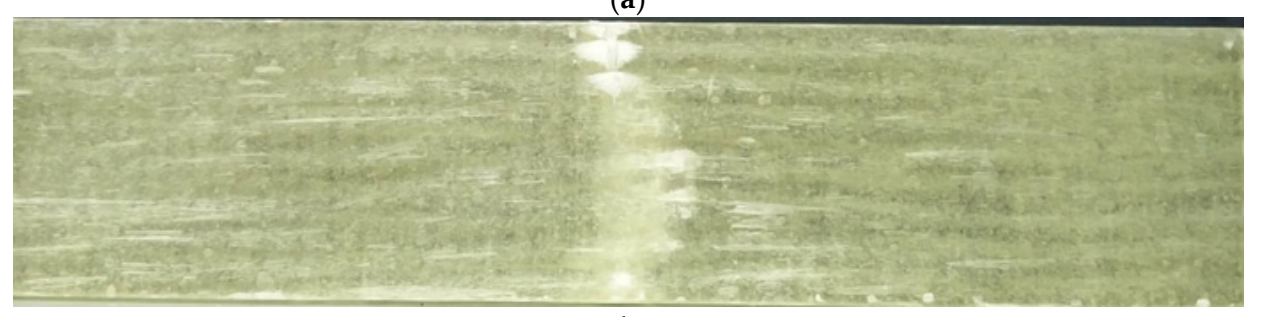

(b)

Figure 10. Photos of a specimen which failed under quasi-static bending; (a) top surface; (b) bottom surface.

\section{Discussion and Concluding Remarks}

This paper was concerned with the damaging of a glass/epoxy composite under mechanical stresses induced in two different ways: abrupt shot, and quasi-static bending. For both cases, owing to the appearance and successive growing of hot spots, it is possible to visualize inline initiation and the 
propagation of damage. In fact, any form of damage, whether cracks with subsequent spreading or fiber breakage, is accompanied by heat release and temperature rise. Conversely, the temperature decreases when stretching the polymer network (thermo-elastic effect). In particular, the cooled zone accounts for the overall affected area; this is mostly evident in the presence of an impact event. The objective of getting information about the material behavior from thermal signatures is successful if, amongst others, the most appropriate infrared imaging device is chosen. In fact, thermal signatures coupled with impact events, even if occurring at low energy/velocity, rapidly evolve (especially cooling effects) and can be captured only with high frame rate and high sensitivity cameras. Instead, the evolution of surface temperatures associated with the gradual quasi-static bending is slow enough to be well visualized with a cheaper camera.

As a common aspect, under both types of load, damaging initiates with the formation of cracks, which reveal themselves through the formation of hot spots. Then, following the time evolution of such hot spots, it is possible to get information on the subsequent damage propagation. However, there are some differences between the temperature-time evolution coupled with each of the two types of test. In fact, the impact is accompanied by a sudden appearance of hot spots in the opposite to the impacted one, meaning that the damage starts on the visualized surface. Conversely, quasi-static bending entails the initial appearance of a hot spot in the loaded specimen surface, which much later is followed by hot spots on the bottom opposite surface; this means that the damage initiates on the front surface in direct contact with the loading nose and then propagates through the entire specimen thickness. In other words, the above described differences in the temperature-time evolution well comply with the different damaging ways of glass/epoxy.

The impact causes an abrupt deformation with a concavity on the impacted side and a protrusion on the other one; the damage (cracks and/or breakage) initiates on the latter side, which is directly viewed by the infrared camera. At low energy impact, without perforation, once the impact ceases and the impactor moves away, the surface recovers its original unbent configuration. Therefore, through surface temperature variations, the damage initiation is sudden visualized as well its subsequent propagation in plane. The propagation in depth may appear as delayed owing to thermal diffusion through the material thickness; of course, this also has to be accounted for with the decrease of thermal diffusivity induced by the damage. Post-processing of the sequences of images and in-depth analysis of the obtained results allows us to understand more of the material behavior under load and to get quantitative information that can contribute to assess the material performance. In fact, it is possible to evaluate the damage extension to a given impact energy from the warm area $\left(A_{\mathrm{h}}\right)$, the peak contact force from the $\Delta T_{\text {Min }}$ peak $\left(t_{\mathrm{p}}\right)$, the duration of the material deformation $(\Delta t)$, and the importance of the damage given by $\Delta T_{\mathrm{Max}}$ and $\Delta t_{\mathrm{D}}$ values (Table 1). In addition, the overall impact on the affected area might be evaluated from the extension of the cooled area.

Under quasi-static bending, glass/epoxy undergoes failure in compression, which means that the first hot spots appear over the loaded surface, or better over the side opposite to that viewed by the infrared camera (Figure 7). Then, only the hot spot appearing on the top (Figures 6 and 8) over the specimen thickness can be promptly captured as it forms. The outer side, being in tension, displays more likely first cooling effects before being involved by breakage and warming-up coupled effects.

As a final comment, results obtained through inline monitoring with infrared thermography may contribute to finding a correlation between impact energy and occurred damage, which may help designers of new materials. However, this is a long way off, as it involves collecting data with a vast variety of materials subjected to different types of tests and varying the testing conditions. Currently, only a few results are available.

Supplementary Materials: The following are available online at www.mdpi.com/2076-3417/8/2/301/s1, Video S1: GFRP-12J.

Author Contributions: Authors have contributed equally to the work. The authors together planned the work, in particular, S. Boccardi mostly took care of image post-processing while C. Meola wrote the paper. S. Boccardi, C. Meola and G.M. Carlomagno all cheched and revised the paper. 
Conflicts of Interest: The authors declare no conflict of interest.

\section{References}

1. Hull, D.; Clyne, T.W. An Introduction to Composite Materials; Cambridge University Press: Cambridge, UK, 1996.

2. Soutis, C. Fiber reinforced composite in aircraft construction. Prog. Aerosp. Sci. 2005, 41, 143-151. [CrossRef]

3. Plackett, D.; Andersen, T.L.; Pedersen, W.B.; Nielsen, L. Biodegradable composites based on 1-polylactide and jute fibres. Compos. Sci. Technol. 2003, 63, 1287-1296. [CrossRef]

4. Lee, S.H.; Wang, S. Biodegradable polymers/bamboo fiber biocomposite with bio-based coupling agent. Compos. A 2006, 37, 80-91. [CrossRef]

5. Gupta, N.; Jain, A.K.; Asokan, P. Mechanical characterization of fully bio-degradable jute fabric reinforced polylactic acid composites. Int. J. Adv. Eng. Res. Stud. 2014, 111-113. Available online: http:/ / www.technicaljournalsonline.com/ijaers/VOL\%20III/IJAERS\%20VOL\%20III\%20ISSUE\%20IV\% 20JULY\%20SEPTEMBER\%202014/509.pdf (accessed on 19 February 2017).

6. Richardson, M.O.W.; Wisheart, M.J. Review of low-velocity impact properties of composite materials. Compos. Part A 1996, 27, 1123-1131. [CrossRef]

7. Shi, Y.; Soutis, C. Modelling low velocity impact induced damage in composite laminates. Mech. Adv. Mater. Mod. Processes 2017, 3, 14. [CrossRef]

8. Abrate, S. Impact on Composite Structures; Cambridge University Press: Cambridge, UK, 1998.

9. Pérez, M.A.; Martínez, X.; Oller, S.; Gil, L.; Rastellini, F.; Flores, F. Impact damage prediction in carbon fiber-reinforced laminated composite using the matrix-reinforced mixing theory. Compos. Struct. 2013, 104, 239-246. [CrossRef]

10. Abrate, S. Modeling of impacts on composite structures. Compos. Struct. 2001, 51, 129-138. [CrossRef]

11. Feraboli, P.; Kedward, K.T. A new composite structure impact performance assessment program. Compos. Sci. Technol. 2006, 66, 1336-1347. [CrossRef]

12. Tita, V.; de Carvalho, J.; Vandepitte, D. Failure analysis of low velocity impact on thin composite laminates: Experimental and numerical approaches. Compos. Struct. 2008, 83, 413-428. [CrossRef]

13. Gonzalez, E.V.; Maimf, P.; Camanho, P.P.; Turon, A.; Mayugo, J.A. Simulation of drop-weight impact and compression after impact tests on composite laminates. Compos. Struct. 2012, 94, 3364-3378. [CrossRef]

14. Choi, I.H. Low-velocity impact analysis of composite laminates under initial in-plane load. Compos. Struct. 2008, 86, 251-257. [CrossRef]

15. Olsson, R. Analytical prediction of large mass impact damage in composite laminates. Compos. Part A 2001, 32, 1207-1215. [CrossRef]

16. Meola, C.; Carlomagno, G.M. Impact damage in GFRP: New insights with Infrared Thermography. Compos. Part A 2010, 41, 1839-1847. [CrossRef]

17. Meola, C.; Carlomagno, G.M.; Bonavolontà, C.; Valentino, M. Monitoring composites under bending tests with infrared thermography. Adv. Opt. Technol. 2012, 2012, 720813. [CrossRef]

18. Boccardi, S.; Carlomagno, G.M.; Meola, C.; Russo, P.; Simeoli, G. Monitoring mechanical loading of polylactic acid matrix jute reinforced composites. In Proceedings of the XXIII Conference of the Italian Association of Theoretical and Applied Mechanics (AIMETA), Salerno, Italy, 4-7 Settembre 2017; Ascione, L., Berardi, V., Feo, L., Fraternali, F., Tralli, A.M., Eds.; pp. 1934-1942, ISBN 978-889-42484-7-0.

19. Lisle, T.; Bouvet, C.; Pastor, M.L.; Margueres, P.; Corral, R.P. Damage assessment of thin woven composite subjected to quasi-static tensile loading using infrared thermography. In Proceedings of the ECCM15-15th European Conference on Composite Materials, Venice, Italy, 24-28 June 2012.

20. Meola, C.; Boccardi, S.; Boffa, N.D.; Ricci, F.; Simeoli, G.; Russo, P.; Carlomagno, G.M. New perspectives on impact damaging of thermoset- and thermoplastic-matrix composites from thermographic images. Compos. Struct. 2016, 152, 746-754.

21. Naik, N.K.; Chandra Sekher, Y. Sailendra Meduri, Damage in woven-fabric composites subjected to low-velocity impact. Compos. Sci. Technol. 2000, 60, 731-744. [CrossRef] 
22. Naik, N.K.; Ramasimha, R.; Arya, H.; Prabhu, S.V.; ShamaRao, N. Impact response and damage tolerance characteristics of glass-carbon/epoxy hybrid composite plates. Compos. Part B Eng. 2001, 32, 565-574. [CrossRef]

23. Boccardi, S.; Carlomagno, G.M.; Meola, C. Post-processing of time-sequences acquired during impact tests with the aid of a reference area. In Proceedings of the QIRT Conference, QIRT 2016, Gdansk, Poland, 4-8 July 2016. [CrossRef]

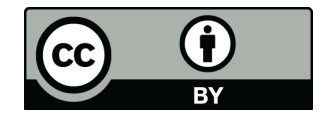

(C) 2018 by the authors. Licensee MDPI, Basel, Switzerland. This article is an open access article distributed under the terms and conditions of the Creative Commons Attribution (CC BY) license (http:/ / creativecommons.org/licenses/by/4.0/). 